\title{
Study on the Main Problems of the Development of Folk Sports and Its Countermeasures*
}

\author{
Jun Wang \\ College of Physical Education \\ Yunnan Agricultural University \\ Kunming, China 650201
}

\author{
Song $\mathrm{Gu}$ \\ College of Physical Education \\ Yunnan Agricultural University \\ Kunming, China 650201 \\ Yu Gan \\ College of Physical Education \\ Yunnan Agricultural University \\ Kunming, China 650201
}

\author{
Zhongbo Wen \\ College of Physical Education \\ Yunnan Agricultural University \\ Kunming, China 650201 \\ Jianke Yang** \\ College of Physical Education \\ Yunnan Agricultural University \\ Kunming, China 650201 \\ **Correspondent Author
}

\begin{abstract}
In the social transition period, there are many difficulties that the folk sports are faced with to be solved urgently in its existence and development. This paper analyzes and studies the current developing situation of folk sports by means of literature review, interview and comparison. And the result shows that the development of folk sportsrequires policy support and organization guarantee; the development of folk sports activities is marginalized, due to change of social form; and the folk sports also are not properly embodied in school PE teaching activities. Hence, guided by the sustainable development thought,the author puts forward that (1) it is necessary to form a long-termmechanism for the development of folk sports in the course of perfecting legal system; (2) bring the folk sports of various places into school PE teaching as special part; (3)promote the market-oriented and integrated development of folk sports; (4) and guide the leisure-oriented and generalized development of folk sports.
\end{abstract}

Keywords—folk sports; existing problem; countermeasure

\section{INTRODUCTION}

Folk sports refers to sports with typical folk custom style, which is created by the masses of people in daily life and labor for fitness and entertainment, and it forms its inherent way of practice and cultural connotation in the long-term spreading period among the people, characterized by entertainment, interestingness, folk custom, game, performance, festivals and so on. It plays a significant role in many kinds of intangible

*Fund Project: General Project of National Social Science Foundation (16BTY105). 2017social science program of the party in Yunnan province :Study interpretation and study implementation the major spiritual of 19th CPC National Congress (YB2017107) cultural heritages in China. However, with the modernization of cities and the tide of economic globalization, the traditional folk sports is losing its cultural soil gradually and is in a titular situation, in addition, with the rise and popularization of western modern sports, confusion of school physical education and the gradual decrease of folk sports talents, folk sports have been facing more and more difficulties in its development. This article starts with the main problems existing in the present developing situation of folk sports in our country and traces back the root causes of its poor development, and on these grounds, it works out the countermeasures for the sustainable development of folk sports.

\section{MAIN PRoBlems EXISTING IN THE DEVELOPMENT OF FOLK SPORTS}

\section{A. Current Developing Situation of Folk Sports}

According to research statistics, there are only over one thousand widespread folk sports exist at present. Most of China's folk sports activities are born in a self-sufficient peasant economy era, and many of which are not adapted to the development of the current society, so that these parts of folk sports will be hard to exist longer. Many far-reaching athletics and sports in the minority groups, such as jumping cattle of the $\mathrm{Yi}$ nationality, jumping horse of the Man nationality, piling sand of the Li nationality and camel races in Xinjiang, etc. have been lost. Also, a large number of minority sports, such as the Sansheng of the Yi nationality, the swinghand dance of the Tujia nationality, the sword dance of the Blang nationality and the sliding cable of the Drung nationality and so on, are in imminent danger. Some of the relevant religious activities are becoming more and more unpopular, 
while some of the traditional sports activities, such as Kompang dance, bell dance, rattle stick dance, steel fork dance and so on, have gone to decay. According to the survey, no matter in the countryside or city, most people choose western sports for fitness instead of folk sports(except martial arts).At present, folk sports are self-organized for self-entertainment, and there is little publicity about folk sports or large-scale organization activities. Although the society has developed into the era of market economy, there is basically no market development and policy support for folk sports; because the education standard of physical education curriculum in our country is formulated by the state, there is no specific requirement for folk sports, so that the teachers training and teaching contents of folk sports appear in the state of free development; affected by the Olympic Plan, the sports authorities at all levels only pay attention on competitive sports and think folk sports of not indispensable.

\section{B. Main Problems Existing in Current Folk Sports}

1) The development of folk sportsrequires policy support and organization guarantee: Under the current situation that the state emphasizes on the development and protection of the traditional cultural heritage, although the governments at all levels have paid much attention to the folk sports, the implementation of the action and the actual development effect are not as expected, mainly because there is few organization management or guidance for the folk sports, and few policy support. Early in the 1970s, the education sector of Taiwan had enacted the General Practice of Folk Sports Activities; while the relevant laws, policies and plans of folk sports in the mainland China are still included in the basic laws and regulations, such as the Sports Law and Outline of National Fitness Program, having no independent folk sports regulations, policies or implementation plans, so that the organization and management departments of folk sports can not make detailed and operable regulations in solving specific problems, which leads to ineffective protection and organization of folk sports activities.

2) The change of social form causes the development of folk sports activities to be marginalized: The present situation of folk traditional sports is the inevitable result of the China's social transition from the agricultural economic society to the industrial economic society. Especially with the rapid development of urbanization and modernization, people's life idea and life style are impacted by the new culture, which makes the folk sports born in the traditional Chinese culture gradually lose the cultural soil that it lives on. With the change of traditional way of life, the identity of traditional culture which has been spread by the ancestors gradually fades, and the enthusiasm of participating in folk sports activities gradually decreases. The popular folk games, which were common in the streets, have been replaced by video products, online games and emerging cultural entertainment places; at the same time, the content of modern sports activities gradually enters and occupies the dominant position, which also accelerates to cause the development of folk sports activities to be marginalized.

3) The folk sportsare not properly carried forward in school PE teaching activities: One of the important ways to develop folk sports is to include it into school physical education. However, the main contents of the physical education standard in school are still running, jumping and throwing projects. In other words, our country's school sports are still dominated by modern sports. The school physical education has been unable to play a positive and effective role in guiding students to participate in the traditional folk sports activities and cultivating the heirs of folk sports. Teacher training is also an important factor that folk sports fail to enter the school physical education successfully, because the teacher's knowledge of folk sports is directly related to the organization and development of the content of the school folk sports activities. It is documented that $79.75 \%$ of the physical education teachers surveyed in 31 primary and middle schools in Shanghai had never had the learning and training experience of folk sports in university. As a result, it can be seen that physical education teachers lack of folk sports skills.

Folk sports games are less restricted in physical education in middle schools that it can be carried out at any time in the PE course. At the beginning of the course, the introduction of folk sports games can help students get well prepared, similar to the teaching link "Preparation Activities". For example, the teacher can divide the students into proper groups for the folk sports game "eagle and chicks" according to the number of students. In the course of the game, the students not only do exercise through the limb acts of "Run, catch, hide", but also spread the cooperation and unity spirit among students. In order to improve the teaching efficiency of physical education in middle schools, teachers should pay attention to the introduction of folk sports games. Before the course, the teacher should screen the folk sports game in accordance with the age characteristics and development requirements of the middle school students, and then combine the sports game with the specific course teaching, innovate and change the rule or application condition of folk sports game, so that the folk sports game will be suitable for middle school physical education. In addition, folk sports games can also be used in the training of students' physical skills. In terms of middle school physical education teaching, it is very difficult to carry out sport skill training and the students are not easy to master the skill essentials, and the traditional classroom mode makes less contribution to taking up the students' learning initiative. The exercise of sports skill is mainly aimed at the cultivation of students' perseverance, which makes the teaching links of physical skills are usually dull, while with the folk sports games, it can realize learning during the play that it not only can teach them sport skills, but also bring them joy, so that the students can master the skills of physical education in ease learning atmosphere, which also contributes to high efficiency of PE teaching in middle school. 


\section{COUNTERMEASURES FOR THE DEVELOPMENT OF FOLK} SPORTS

\section{A. Long-effect Mechanism for the Development of Folk Sports in the Full Forming Process of Legal System}

Firstly, the State must attach importance to relevant protection regulations and rules, which is a powerful guarantee for the development of folk sports. The local governments should select folk sports with strong vitality, great influence and high penetration rate according to the needs for development of folk traditional sports in the region, and include the selected sports in the local cultural protection regulations, so that the inheritance and development of folk traditional sports will have rules and regulations to abide by.

Secondly, the relevant departments should formulate folk sports development plan and include the folk sports into the main contents of the national fitness program, investigate the traditional folk sports in our country, identify key supporting objects to cultivate and promote, give special assistance to support some folk sports to the national or international arena to show and build the traditional sports cultural brand.

Thirdly, create a platform for folk sports communication. Local governments and relevant sports associations should build platforms for the exchange of folk sports activities, promote their distinctive culture and absorb successful experiences, and promote the prosperity and development of folk sports.

\section{B. Promotion of the Market-oriented and Integrated Development of Folk Sports}

As a historical cultural heritage, folk sports can provide not only rich political and cultural resources but also important economic resources for today's society. It is also necessary and feasible to excavate the economic value of the cultural heritage of folk sports for local society and economic development. Promoting the marketization and commercialization of folk sports is an inevitable trend of the development of folk sports. With the help of commercial operation, folk sports can both create economic benefits indirectly and propagandize and popularize it per se, so that the folk sports culture can be integrated into the development of local economy and realize the integrated development of folk sports and local economy. There have been quite a lot of successful experiences in this field, such as the Kite Competition and the Dragon Boat Festival and so on, which not only plays the role of "Cultural force" of folk sports in promotion of local social economy, but also realizes the protection and development of folk sports.

\section{Inclusion of the Local Folk Sports into the Content of Physical Education in School}

Under the current social background of China, school, as the key factor to inherit, carry forward and promote the folk sports, is the main ground to develop folk education. In order to include the folk sports into the school physical education, the first is to get rid of the bound of the competitive-sportsoriented school physical education mode which has been formed for a long time in people's ideology, and place folk sports into local textbooks to form the special content of physical education in local schools; PE teachers are the important factors deciding whether folk sports can successfully be accepted by the school. For a long time, the teacher's strength cultivated in the ordinary colleges and universities in our country mainly focuses on competitive and modern sports. At present, the national traditional physical education in colleges and universities is mainly based on modern martial arts, while the other folk traditional sports account for a very little proportion in teaching content. In addition, the graduates lack the methods and abilities of self-selection and renovation of traditional folk sports, which also exposes the problems existing in the talent training plan of the colleges and universities. For the inheritance and development of folk sports, it is necessary to reform the teaching contents of the colleges and universities that include the content of folk sports in the training plan as a required course, and employ folk PE teachers as part-time teachers, etc. The training of PE teachers with a certain folk sports skill is enabled to enrich the teaching contents of physical education in primary and secondary schools, so as to realize the sustainable development of folk sports.

\section{Leisure-oriented and Generalized Development of Folk Sports}

Folk sports have an inherent advantage in combination with life and leisure. Compared with western physical education, it has its own unique expression style and cultural connotation, and it pays more attention to the function of fitness and leisure entertainment. In the development of welloff society, folk sports should not only emphasize the essential characteristics of physical fitness, but also pay attention to people's healthy way of life and high-quality living content, and create a humanized environment and family atmosphere while bring effective fitness. Living and fitness, leisure and entertainment are the basic ways to develop and innovate in folk sports. We need to create space for the development of folk sports close to life and leisure with human-oriented content and human-oriented method, so as to enjoy the happiness of folk sports to people and make it a part of people's life. In the process of enriching and improving the form of folk sports organizations, it has become the mainstream of folk sports activities to make it popularized, diversified, personalized and family-oriented.

\section{CONCLUSION}

With the development of the socialist market economy and the comprehensive reform and construction of various causes, it is the responsibility and obligation of governments, schools, enterprises and society at all levels to make folk sports keep pace with the times. It is necessary for our country to work out the Regulations on the Promotion of Folk sports Activities and the sports organizations to develop folk sports cause in a planned way, from disorder to order and from informal to formal. The rejuvenation of the Chinese nation is essentially a revival of Chinese culture, while, the folk sports are right a precious cultural heritage for the future generations. In the future, it is more to inherit and develop the folk sports causes organically in combination with the modern society than just innovation and development, so as to better enrich the cultural 
life content of modern people, serve and construct a harmonious society. Hence, we need to, guided by the scientific development view and relying on the wisdom and participation of the whole nation, consider and support the folk sports causes from the view of protecting the traditional culture of the nation and improving the quality of the whole people and gradually restore the prosperity of the folk sports causes.

\section{REFERENCES}

[1] Zhang Jizhen, Yu Zhonggan. Practical Study on the Protection and Development of Folk Sports in China[J].Shanghai: Journal of Shanghai University of Sport, 2007.11. 张基振, 虞重干. 中国民间体育保护与 发展实践论[J].上海: 上海体育学院学报, 2007.11

[2] Wu Jian.Research on the Development Trend of Folk Sports in PostOlympic Era[M].Zhejiang: Zhejiang Sport Science, 2009.9. 吴剑. 后 奥运时代民间体育发展趋势的研究[MJ.浙江：浙江体育科学, 2009.9

[3] Shao Rong, Ke Ling.Thought on Cultural Elements in Chinese Folk Sports [J].Beijing: Journal of Beijing Sport University, 2004.6. 邵荣,柯 玲. 中国民间体育的文化思索[J].北京: 北京体育大学学报, 2004.6

[4] GuoQiongzhu.The Survival, Protection and Development of Rural Traditional Sports in Social Transition [J].Fujian: Journal of Xiamen University, 2008.2. 郭琼珠. 社会转型期村落传统体育的生存、保护 与发展 [J].福建: 厦门大学学报, 2008.2

[5] Zhang Jizhen, YuZhonggan, ZouZhimin.Investigation and Reflection on the Current Situation of the Participation of Shanghai Young Children in Folk Sports Activities[J].Shanghai: Journal of Shanghai University of Sport, 2006, 11. 张基振,虞重干,邹志敏. 上海市青少年儿童参与民 间体育活动现状的调查与思考 $[\mathrm{J}]$. 上海: 上海体育学院学报, 2006,.11

[6] Li Dingzhong. Analysis onthe Cultural Elements in Plight of Folk Sports in China[M].Guangdong: Theoretical New Exploration. 2009.3. 李定忠. 对我国民间体育流传困境的文化学分析 [M].广东. 理论探 新. 2009.3

[7] Wang Longfei, Chen Shiqiang.Protection of theIntangible Cultural Heritage and National Traditional Sports [J].Sports Culture Guide. 2008. 11. 王龙飞,陈世强. 非物质文化遗产与民族传统体育保护[J]. 体育 文化导刊.2008.11

[8] ZhanYuzhen, Wang Junqi.Analysis on theFolk Sports and Civil Sports[J]. Sports Culture Guide. 2009.4. 占玉珍,王俊奇.. 民俗体育与 民间体育辨析 [J]. 体育文化导刊.2009.4 